\title{
PELAKSANAAN E-LEARNING UNTUK MATA KULIAH DASAR KEPENDIDIKAN
}

\author{
Rugaiyah \\ e-mail: rugaiyah_fitri@yahoo.co.id \\ Manajemen Pendidikan, FIP Universitas Negeri Jakarta
}

\begin{abstract}
Abstrak: Penelitian ini bertujuan untuk mendapatkan informasi tentang pelaksanaan e-learning untuk mata kuliah MKDK di Universitas Negeri Jakarta. Penelitian ini dilakukan di Universitas Negeri Jakarta mulai Mei hingga November 2012. Populasi dalam penelitian ini adalah Dosen Mata Kuliah Dasar Kependidikan dan Mahasiswa peserta MKDK FIP Universitas Negeri Jakarta. Adapun sampel penelitian ditetapkan dengan proportional purposive sampling diambil dari masing-masing jurusan/program studi. Metode yang digunakanmetode deskriptif dan metode eksploratif. Pengumpulan data dilakukandengan menggunakan angket dan ditunjang dengan interview/wawancara. Hasil penelitian menunjukkan: Sebagian besar pelaksanaan e-learning yang dilakukan oleh dosen MKDK sudah menggunakan laptop dan LCD sebagai alat bantu mengajar, mayoritas dosen tidak menggunakan CD pembelajaran dan OHP sebagai alat bantu mengajar, hampir di seluruh gedung ketersediaan jaringan hotspot dan kemudahan dalam mengaksesnya masih sangat minim, e-learning sangat membantu mahasiswa dalam memahami materi kuliah, hampir semua mahasiswa memiliki laptop dan modem sebagai alat dalam menunjang pelaksanaan e-learning, kebanyakan mahasiswa menggunakan handphone dalam mengakses materi kuliah, pemahaman mahasiswa terkait e-learning sudah baik, sebagian besar setuju dengan pelaksanaan e-learning karena dengan e-learning memudahkan mahasiswa untuk mengakses materi tanpa terhalang waktu dan tempat, lebih efisien, mudah, cepat dan efektif, mahasiswa membutuhkan $e$-learning melalui blog/ skype/ youtube ditunjang oleh dosen yang profesional, pembelajaran yang mudah diakses, tidak membosankan.
\end{abstract}

Kata Kunci : Mata Kuliah Dasar Kependidikan (MKDK), alat bantu pembelajaran, e-learning.

\section{IMPLEMENTATION OF E-LEARNING IN EDUCATION BASIC COURCES}

\begin{abstract}
Abstrak: This study aims to obtain information on the implementation of e-learning in Education Basic Courses (MKDK) at State University of Jakarta. The study was conducted at the Faculty of Education from May through November 2012. The population of the study covered lecturers and students of MKDK and the samples were selected by proportional purposive sampling technique. The data were collected using questionnaire and supported by interview guide. The results show that majority of the lecturers implement e-learning by using laptops and $L C D$, majority of the faculty do not use $C D$ and OHP as teaching aids, hotspot network availability and the access very poor in almost all buildings, e-learning greatly assists students to understand the course material, almost all of the students have laptops and modems to support the lecture, most of the students use mobile phones to access the course material, and e-learning can facilitate students to access material unhindered by time and place, more efficiently, easily, quickly and effectively. The students need e-learning using blog / skype / youtube supported by professional lecturers, learning should be easily accessible and not boring.
\end{abstract}

Keywords: education basic courses, e-learning, teaching and learning aids.

\section{PENDAHULUAN}

Pada era globalisasi ini, teknologi dan informasi berkembang dengan sangat pesat. Perkembangan teknologi dan informasi ini sangat berguna dalam dunia pendidikan. Dalam dunia pendidikan, perkembangan informasi dan teknologi dapat diaplikasikan dalam penggunaan e-learning pada proses belajar mengajar. E-learning merupakan pembelajaran dengan menggunakan jasa perangkat elektronik, bisa berupa: komputer, radio, tape audio/video, TV interaktif, CD Room, maupun LCD 
proyektor. Akan tetapi, banyak kalangan menganggap bahwa e-learning merupakan pembelajaran berbasis internet. Dalam Wikipedia dituliskan bahwa dengan penggunaan e-learning, peserta didik tidak perlu duduk dengan manis di ruang kelas untuk menyimak materi yang disampaikan oleh dosen. E-learning juga dapat mempersingkat jadwal target waktu pembelajaran, dan menghemat biaya yang harus dikeluarkan oleh sebuah program studi atau program pendidikan (www.id.wikipedia.org).

E-learning dalam penelitian ini adalah penggunaan bahan-bahan ajar dalam pembelajaran dalam pelaksanaan perkuliahan yang dilakukan oleh dosen, seperti : electrinoic slide, compact disk, video compact disk, dvd, internet, dan lain sebagainya. Pelaksanaan E-learning ini bertujuan untuk meningkatkan kualitas pembelajaran mahasiswa dan peningkatan kompetensi dosen khususnya kreativitas dosen dalam penggunaan media-media pembelajaran yang bervariasi di kelas sehingga para mahasiswa tidak merasa jenuh dengan media-media yang monoton.

Meskipun pelaksanaan e-learning dapat membantu mahasiswa dalam meningkatkan kualitas belajar, tetapi berdasarkan hasil pengamatan sementara, peneliti menemukan terdapat sebagian dosen yang belum melaksanaan e-learning secara optimal, sehingga pelaksanaan e-learning dalam kegiatan belajar mengajar belum terealisasi dengan baik. Ada beberapa kemungkinan yang menyebabkan kondisi tersebut terjadi, di antaranya: fasilitas yang belum memadai, ketidaksiapan dosen menggunakan perangkat elektronik, dan keengganan mahasiswa dalam menggunakan perangkat elektronik. Sedangkan dalam e-learning, dosen dituntut memiliki kecakapan dalam penggunaan perangkat elektronik, seperti komputer, laptop dan juga penggunaan internet sehingga e-learning dapat berjalan dengan lancar. Selain itu, perguruan tinggi juga perlu menyediakan fasilitas-fasilitas yang dibutuhkan untuk mendukung e-learning sehingga pembelajaran ini dapat berjalan dengan baik.

Agar pelaksanaan e-learning dapat berjalan dengan baik, harus ada sinergi antara dosen, mahasiswa, dan fasilitas yang tersedia di kelas ataupun di lingkungan universitas. Universitas harus menyediakan jaringan internet yang dapat digunakan mahasiswa di setiap ruang kelas dan juga fasilitas lainnya yang dapat menunjang proses e-learning. Dengan adanya sinergi tersebut, maka e-learning dapat berjalan dengan baik.

Berdasarkan uraian di atas, maka peneliti ingin melihat bagaimana pelaksanaan e-learning dalam kegiatan belajar mengajar pada mata kuliah MKDK di Universitas Negeri Jakarta?

Untuk mendukung penelitian ini, maka terdapat beberapa kajian teori yang dijelaskan sebagai berikut: a. Pendekatan E-learning

Pendekatan e-learning atau electronic learning merupakan salah satu pendekatan pembelajaran dengan menggunakan jasa bantuan perangkat elektronik. Secara umum, e-learning didefinisikan sebagai sistem atau konsep pendidikan yang memanfaatkan teknologi informasi/elektronik dalam proses belajar mengajar. Teknologi informasi itu seperti: komputer, teknologi jaringan, serta teknologi telekomunikasi seperti radio, telepon dan satelit. Semua itu ditujukan agar daya serap mahasiswa atas materi yang diajarkan serta kualitas materi pembelajaran lebih meningkat. Salah satu bagian dari kegiatan e-learning yang menggunakan fasilitas internet adalah distance-learning yang merupakan proses pembelajaran di mana dosen dan mahamahasiswa tidak ada dalam satu ruangan kelas secara langsung. E-learning adalah pembelajaran jarak jauh yang menggunakan teknologi komputer, atau biasanya Internet (Henderson, 2003). E-learning memungkinkan pembelajar untuk belajar melalui komputer di tempat mereka masing-masing tanpa harus secara fisik pergi mengikuti pelajaran di kelas.

E-learning meliputi pembelajaran pada semua tingkatan, formal maupun nonformal, yang menggunakan jaringan komputer (intranet maupun ekstranet) untuk pengantaran bahan ajar, interaksi, dan/atau fasilitasi (Tinio dalam Hartley: 2001). E-learning as learning enabled by the internet. Intranets, and other electronic network. Artinya, e-learning merupakan suatu jenis belajar mengajar yang memungkinkan tersampaikannya bahan ajar ke mahasiswa dengan menggunakan media Internet, Intranet atau media jaringan komputer lain (Hartley, 2001).

Dalam berbagai literatur, e-learning didefinisikan sebagai: a generic term for all technologically supported learning using an array of teaching and learning tools as phone brdging, audio and videotapes, teleconferencing, satellite transmissions, and the more recognized web-based training or computer aided instruction also commonly referred to as online course (Soekartawi dalam buku ajar TBP). Merujuk literatur ini, maka e-learning dapat diartikan sebagai pembelajaran yang pelaksanaannya didukung oleh jasa teknologi seperti telepon, audio, videotape, transmisi satelit, atau komputer.

Secara harfiah, pengertian e-learning berasal dari kata e- dan learning diartikan pembelajaran 
elektronik, hal tersebut dimaksudkan sebagai pembelajaran yang memanfaatkan elektronik untuk menunjang kegiatan pembelajaran, baik di kelas maupun di luar kelas. Pembelajaran ini sering dimaknakan pembelajaran yang hanya menggunakan perangkat komputer, sebenarnya peralatan tersebut hanya salah satu perangkat, masih ada perangkat lain yang dapat digunakan untuk e-learning, seperti: radio, tape, audio/video, tv interaktif, CD room, LCD Proyektor, OHP, dll. Media-media elektronik tersebut sangat membantu mahamahasiswa agar bisa lebih menguasai materi kuliah.

b. Manfaat E-Learning

Manfaat pembelajaran elektronik terdiri atas 4 hal, yaitu: (1) meningkatkan kadar interaksi pembelajaran antara peserta didik dengan dosen atau instruktur (enhance interactivity); (2) memungkinkan terjadinya interaksi pembelajaran dari mana dan kapan saja (time and place flexibility); (3) menjangkau peserta didik dalam cakupan yang luas (potential to reach a global audience); (4) mempermudah penyempurnaan dan penyimpanan materi pembelajaran (easy updating of content as well as archivable capabilities) (Bates \& Wukf: 1996).

\section{c. Efektifitas Pelaksanaan E-Learning}

Pelaksanaan programe-learning harus didukung oleh civitas lembaga, mulai dari pimpinan, dosen, mahasiswa, tenaga tata usaha, dan staf penunjang lainnya. E-learning membutuhkan dukungan dari semua pihak yang saling terintegrasi untuk menjalankan perannya masing-masing untuk melaksanakan e-learning.

Pimpinan lembaga merupakan motor penggerak dalam keberhasilan e-learning, karena dengan adanya dukungan pimpinan maka pimpinan akan menyediakan segala fasilitas pendukung guna berjalannya e-learning, mulai dari menyediakan jaringan hotspot, radio, tape, audio/video, tv interaktif, CD pembelajaran, LCD Proyektor, dan dukungan fasilitas komputer yang disediakan di laboratorium komputer beserta akses internet dengan kapasitas tinggi.

Dosen berperan penting dalam pelaksanaan e-learning. Walaupun semua perangkat sudah disediakan, jika dosen enggan atau belum mampu menerapkan e-learning dalam perkuliahan, maka tujuan pembelajaran tidak akan tercapai. Untuk itu, dosen harus mampu mengikuti perkembangan teknologi, terutama menggunakan perangkat elektronik sebagai pendukung pembelajaran. Dosen dituntut untuk mampu menyusun materi kuliah yang interaktif sesuai perkembangan teknologi.
Mahasiswa yang merupakan sasaran e-learning juga perlu mengikuti perkembangan teknologi, terutama dalam menggunakan perangkat elektronik dalam mendukung belajarnya. Dengan dukungan fasilitas, mahasiswa diharapkan dapat memanfaatkannya secara optimal.

Selain mahasiswa dan dosen, terdapat beberapa staf penunjang yang memiliki tugas dalam pelaksanaan e-learning. Tenaga tata usaha merupakan salaah satu staf penunjang tang bertugas menyiapkan dan memelihara fasilitas yang sudah ada agar dapat digunakan. Tata usaha juga perlu memahami prosedur penggunaan dan pemeliharaan perangkat elektronik sehingga tidak mudah rusak.

\section{METODE PENELITIAN}

Pendekatan yang digunakan dalam penelitian ini adalah pendekatan survey dan analisa data sekunder dengan metode eksploratif dan deskriptif.

Penelitian ini akan dilakukan Universitas Negeri Jakarta dan waktu yang dibutuhkan dalam penelitian ini mulai dari Mei 2012 s.d November 2012.

Populasi dalam penelitian ini adalah Dosen Mata Kuliah Dasar Kependidikan dan Mahasiswa peserta MKDK Universitas Negeri Jakarta. Adapun sampel penelitian ditetapkan dengan proportional purposive sampling diambil dari masing-masing jurusan/ program studi secara proporsional. Pengumpulan data dilakukan dengan menggunakan angket. Selain itu untuk mendukung keabsahan data, maka ditunjang dengan interview/wawancara.

\section{HASIL DAN PEMBAHASAN}

Penelitian ini mengungkap tentang pelaksanaan e-learning yang telah dilakukan pada kegiatan pembelajaran MKDK yang meliputi: penggunaan alat bantu pengajaran oleh dosen, jaringan hotspot, penggunaan IT oleh dosen dan mahasiswa, kebermanfaat e-learning bagi mahasiswa, dan hardware pendukung bagi mahasiswa.

Penggunaan Alat Bantu Pengajaran Oleh Dosen Mkdk Yang Menunjang Pelaksanaan E-Learning

Pelaksanaan e-learning dengan menggunakan alat bantu pengajaran, meliputi penggunaan laptop, LCD, CD pembelajaran, dan OHP. Berdasarkan hasil penyebaran instrumen ke 129 responden diperoleh informasi bahwa 69,72\% mengajar dengan menggunakan laptop dan sebanyak 30,28\% dosen belum menggunakan laptop dalam mengajar. Selanjutnya sebanyak 71,56\% dosen mengajar dengan menggunakan LCD dan 28,44\% tidak menggunakan 
LCD dalam mengajar. Terkait penggunaan CD pembelajaran hanya sebagian kecil saja yang menggunakan $\mathrm{CD}$ pembelajaran yaitu sebanyak $26,61 \%$ sedangkan sebagian besar yaitu sebanyak $73,39 \%$ belum menggunakan CD pembelajaran. Terakhir penggunaan OHP, sebanyak 25,69\% dosen yang masih menggunakan OHP sedangkan $74,31 \%$ sudah tidak menggunakan OHP dalam pembelajaran. a. Jaringan hotspot penunjang pelaksanaan e-learning Akses hotspot sangat dibutuhkan dalam pelaksanaan e-learning, terkait jaringan hotspot kondisi di tiap gedung berbeda, ditemukan sebagai berikut. Pertama, untuk di gedung Daksinapati lantai 3 yang dijadikan responden sebanyak 48 mahasiswa. Diperoleh informasi $45,83 \%$ menjawab di dalam kelas terdapat jaringan hotspot dan $54,17 \%$ menjawab di dalam kelas belum terdapat jaringan hotspot. Sebanyak 27,08\% menjawab jaringan hotspot di dalam kelas mudah diakses dan 72,92\% menjawab jaringan hotspot di dalam kelas sulit diakses. Selanjutnya terkait jaringan hotspot di luar kelas, sebanyak 56,25\% menjawab mudah diakses dan $43,75 \%$ sulit diakses.

Kedua, untuk di gedung E lantai 1 dan 2 yang dijadikan responden sebanyak 33 mahasiswa. Diperoleh informasi $48,48 \%$ menjawab di dalam kelas terdapat jaringan hotspot dan 51,52\% menjawab di dalam kelas belum terdapat jaringan hotspot. Sebanyak 33,33\% menjawab jaringan hotspot di dalam kelas mudah diakses dan $66,67 \%$ menjawab jaringan hotspot di dalam kelas sulit diakses. Selanjutnya terkait jaringan hotspot di luar kelas, sebanyak 30,30\% menjawab mudah diakses dan $69,70 \%$ sulit diakses.

Ketiga, untuk di gedung L (FT) lantai 3 yang dijadikan responden sebanyak 13 mahasiswa. Diperoleh informasi 23,08\% menjawab di dalam kelas terdapat jaringan hotspot dan $76,92 \%$ menjawab di dalam kelas belum terdapat jaringan hotspot. Sebanyak $100 \%$ menjawab jaringan hotspot di dalam kelas tidak mudah diakses. Selanjutnya, terkait jaringan hotspot di luar kelas, sebanyak 30,77\% menjawab mudah diakses dan $69,23 \%$ sulit diakses.

Keempat, untuk di gedung L (FT) lantai 4 yang dijadikan responden sebanyak 15 mahasiswa. Diperoleh informasi 100\% menjawab di dalam kelas tidak terdapat jaringan hotspot. Sebanyak 13,33\% menjawab jaringan hotspot di dalam kelas mudah diakses dan $86,67 \%$ menjawab jaringan hotspot di dalam kelas sulit diakses. Selanjutnya terkait jaringan hotspot di luar kelas, sebanyak 33,33\% menjawab mudah diakses dan $66,67 \%$ sulit diakses.

Kelima, untuk di gedung O (FBS) lantai 1 yang dijadikan responden sebanyak 20 mahasiswa.
Diperoleh informasi 5\% menjawab di dalam kelas terdapat jaringan hotspot dan 95\% menjawab di dalam kelas belum terdapat jaringan hotspot. Sebanyak 15\% menjawab jaringan hotspot di dalam kelas mudah diakses dan $85 \%$ menjawab jaringan hotspot di dalam kelas sulit diakses. Selanjutnya terkait jaringan hotspot di luar kelas, sebanyak 75\% menjawab mudah diakses dan $25 \%$ sulit diakses.

b. Penggunaan IT oleh dosen dan mahasiswa dalam menunjang pelaksanaan e-learning

Dalam penggunaan IT oleh dosen dan mahasiswa meliputi: pencarian referensi melalui internet, pengumpulan tugas melalui email, dosen memberikan kuliah melalui blog, dan dosen mewajibkan mendownload materi kuliah di blog. Dalam hal pencarian referensi melalui internet, sebanyak $89,91 \%$ mahasiswa menggunakan internet untuk mencari referensi dan sebanyak 10,09\% belum menggunakan internet. Dalam hal pengumpulan tugas kuliah melalui email sebanyak $40,37 \%$ mahasiswa mengumpulkan tugas kepada dosen melalui email dan 59,63\% tidak menggunakan email dalam mengumpulkan tugas. Mengenai pemberian materi kuliah oleh dosen melalui blog hanya 10,09\% saja yang menggunakan blog, sedangkan sebanyak $89,91 \%$ tidak menggunakan blog. Terakhir mengenai download materi melalui blog hanya sekitar 13,76\% dosen MKDK mewajibkan mahasiswa mendownload materi kuliah di blog sedangkan 86,24\% dosen MKDK tidak mewajibkan mahasiswa mendownload materi kuliah di blog.

c. Kebermanfaatan pelaksanaan e-learning bagi mahasiswa

Kebermanfaatan peleksanaan e-learning dalam belajar diperoleh informasi sebanyak 67,89\% mahasiswa terbantu jika belajar menggunakan e-learning, sedangkan 32,11\% tidak terbantu dengan e-learning. Mengenai kepuasan mahasiswa sebanyak $70,64 \%$ mahasiswa merasa senang belajar dengan menggunakan e-learning dan 29,36\% mahasiswa tidak senang belajar dengan menggunakan e-learning. Terkait dengan kesulitan belajar, sebanyak 21,1\% merasa kesulitan belajar dengan menggunakan e-learning sedangkan 78,9\% tidak menemui kesulitan belajar dengan menggunakan e-learning. Selanjutnya, terkait kemudahan dalam menggunakan e-learning sebanyak $58,72 \%$ dosen yang mengajar dengan menggunakan e-learning memudahkan mahasiswa memahami materi kuliah dan sebanyak $41,28 \%$ dosen yang mengajar dengan menggunakan e-learning tidak memudahkan mahasiswa memahami materi kuliah.

d. Hardware pendukung bagi mahasiswa dalam 


\section{pelaksanaan e-learning}

Hardware pendukung yang dimiliki mahasiswa dalam menunjang pelaksanaan e-learining yaitu laptop/notebook. Sebagian besar mahasiswa memiliki laptop/notebook yaitu sebanyak $87,16 \%$, hanya sebagian kecil saja yang belum memiliki yaitu sebanyak $12,84 \%$. Dalam penggunaan modem, sebagian besar mahasiswa juga sudah memiliki modem yaitu sebanyak $80,73 \%$ sedangkan sisanya $19,27 \%$ tidak memiliki modem. Modem merupakan salah satu kebutuhan yang diperlukan untuk mengakses materi perkuliahan. Hal ini dapat dilihat dari 93,58\% responden menjawab ya, hanya 5,5\% saja yang menjawab tidak. Selanjutnya kegunaan laptop/ notebook, sebanyak $94,5 \%$ responden menjawab bahwa laptop/notebook merupakan peralatan yang dibutuhkan dalam kegiatan perkuliahan sedangkan 5,5\% menjawab tidak. Selain itu kegunaan laptop/ notebook dalam membantu menyelesaikan tugas kuliah sebanyak 99,08\% menjawab sangat membantu menyelesaikan tugas kuliah dan hanya $0,92 \%$ saja yang menjawab tidak. Terkait dengan penggunaan handphone dalam membantu mengakses materi perkuliahan, sebanyak $86,24 \%$ responden mengatakan bahwa handphone dapat membantu mengakses materi perkuliahan sedangkan sisanya $13,76 \%$ menjawab tidak.

Selain menggunakan pertanyaan tertutup, diberikan juga pertanyaan terbuka, yang meliputi: Pengetahuan tentang e-learning, kebutuhan akan pelaksasanaan e-learning, manfaat e-learning, pelaksanaan e-learning yang diinginkan, serta saran untuk peningkatan kualitas pelaksanaan e-learning. Terkait pengetahuan tentang e-learning, pemahaman mahasiswa mengenai e-learning yakni e-learning merupakan: pembelajaran berbasis komputer dan internet, pembelajaran berbasis media elektronik, belajar dengan menggunakan LCD dan Laptop, metode pembelajaran yang tidak mengharuskan mahasiswa bertatap muka langsung dengan dosen namun tetap memperhatikan kaidah sistem belajar mengajar yang efektif dengan menggunakan internet, belajar on-line melalui internet yang bisa diakses setiap waktu.

Pertanyaan berikutnya mengenai kebutuhan akan pelaksanaan e-learning, hampir seluruh responden membutuhkan pelaksanaan e-learning, sebagian kecil menjawab tidak selalu disesuaikan dengan materi yang diajarkan. Pertanyaan mengenai manfaat pelaksanaan e-learning, berikut jawaban responden: memudahkan akses bila mahasiswa/ dosen tidak hadir, mudah dalam mendapat materi, membantu belajar, mendapat pengetahuan teknologi dan mempermudah mengakses data, menjadi tahu materi yang dipelajari, penyampaian materi lebih jelas, lebih efisien, mudah, cepat dan efektif, mudah diakses tanpa melihat waktu dan tempat, serta memudahkan mencari info dari berbagai sumber.

Adapun pelaksanaan e-learning yang mahasiswa butuhkan adalah: pembelajaran dengan menggunakan internet/website, pembelajaran yang mudah diakses, pembelajaran melalui blog/website, pembelajaran melalui video webcame (Skype/Youtube). Adapun saran yang diberikan mahasiswa untuk peningkatan kualitas e-learning antara lain: terdapat hotspot yang mudah diakses, materi lebih lengkap dan mudah diakses, jaringan internet kampus diperluas, lebih banyak menggunakan media elektronik, serta tersedianya akses free hotspot di ruang kelas,

Setelah menjelaskan hasil pada penelitian ini, maka pembahasan pada penelitian ini adalah:

Pelaksanaan e-learning dilihat dari penggunaan alat bantu pengajaran seperti penggunaan laptop dan LCD sebagian besar $(+70 \%)$ dosen MKDK sudah menggunakan, berarti hampir seluruh dosen sudah menggunakan laptop dan LCD sebagai alat bantu mengajar. Tetapi jika dilihat dari penggunaan CD pembelajaran dan OHP mayoritas dosen tidak menggunakannya (+73\%). Hal ini disebabkan masih terbatasnya $\mathrm{CD}$ pembelajaran yang dimiliki oleh MKDK dibandingkan jumlah dosen yang mengajar dan untuk penggunaan OHP sudah sangat jarang digunakan karena saat ini sudah ada fasilitas LCD sebagai pengganti OHP.

Selanjutnya, terkait jaringan hotspot dalam pelaksanaan e-learning. Hasil penyebaran instrumen terdapat perbedaan antar gedung. Untuk ketersediaan jaringan hotspot dalam pelaksanaan e-learning di dalam kelas di gedung L (FT) lantai 4 tidak ada sama sekali, untuk kemudahan dalam mengakses di gedung $\mathrm{L}$ (FT) lantai 3 dan 4 tidak bisa mengakses sama sekali dan untuk kemudahan dalam mengakses di luar kelas di gedung O (FBS) lantai 1 sebanyak 75\% responden menjawab sulit dalam mengakses. Dari mayoritas jawaban mahasiswa, maka hampir di seluruh gedung ketersediaan jaringan hotspot dan kemudahan dalam mengaksesnya masih sangat minim, implikasinya e-learning belum dapat berjalan efektif.

Terkait penggunaan information and technologi (IT) dalam pelaksanaan e-learing baik oleh dosen dan mahasiswa dalam hal pencarian referensi melalui internet sebagian besar sudah menggunakan internet untuk keperluan perkuliahan yakni sebanyak 89,91. Ini menunjukkan bahwa keberadaan internet sangat 
menunjang proses belajar mengajar baik untuk dosen maupun mahasiswa. Internet sudah menjadi suatu kebutuhan untuk kalangan akademisi. Akan tetapi, dosen yang meminta mahasiswa untuk mengumpulkan tugas melalui email hanya sebagian saja yang sudah melakukannya (hanya 40,3\%). Sedangkan sebagian lagi belum menggunakan fasilitas email. Sebenarnya lebih efisiien jika mengumpulkan tugas melalui email dan juga tidak menghamburhamburkan kertas. Penggunaan blog di kalangan dosen dalam memberikan materi kuliah hanya 10,09\%. Hal ini perlu diberikan pemahaman kepada dosen mengenai manfaat penggunaan blog dalam perkuliahan, sehingga para dosen akan terstimulus untuk mencoba menggunakan blog dalam mengajar. Karena dosen belum menggunaan fasilitas blog dalam memberikan materi kuliah maka peran dosen dalam menugaskan mahasiswa mengunduh materi melalui blog pun masih sangat sedikit.

Selanjutnya, manfaat pelaksanaan e-learning bagi mahasiswa mayoritas mengatakan bahwa mahasiswa sangat terbantu jika belajar menggunaka e-learning. Dengan adanya e-learning, mahasiswa dapat dengan mudah untuk memahami materi kuliah. Dampaknya mahasiswa merasa senang jika dosen melakukan e-learning dalam pembelajaran akan tetapi bukan berarti mahaiswa tidak mendapat kesulitan ketika belajar menggunakan e-learning, Hal ini bisa disebabkan jaringan hotspot yang tidak mendukung sehingga menyulitkan mahasiswa mengakses materi ajar/mencari berbagai referensi mata kuliah.

Dalam hal kepemilikan laptop dan modem untuk menunjang pelaksanaan e-learnig, lebih dari $90 \%$ mahasiswa sudah memilikinya. Hal ini berarti laptop dan modem sudah menjadi kebutuhan mereka dalam menunjang proses perkuliahan karena jaringan hotspot yang kurang mendukung dan kebutuhan mereka untuk menyelesaikan tugas-tugas yang harus diselesaikan dengan menggunakan bantuan internet. Mengenai penggunaan handphone dalam mengakses materi kuliah lebih dari 86\% mahasiswa menggunakannya. Saat ini berbagai tipe handphone menyediakan fasilitas internet yang memungkinkan mereka lebih mudah dalam menyelesaikan tugastugas yang diberikan dosen di ruang kuliah untuk segera diselesaikan saat itu juga.

Pemahaman mahasiswa terkait e-learning sudah baik. Dalam pelksanaan e-learning dosen dan mahasiswa memanfaatkan perangkat elektronik, seperti LCD, laptop, dan internet dengan segala fasilitas yang tersedia di dalamnya. Mengenai kebutuhan akan akan e-learning, tidak seluruhnya setuju dengan penggunaan e-learning, menurut mahasiswa disesuaikan dengan materi yang diajarkan. Akan tetapi, sebagian besar setuju dengan penerapan e-learning. Dengan e-learning memudahkan mahasiswa untuk mengakses materi tanpa terhalang waktu dan tempat, lebih efisien, mudah, cepat dan efektif. Saat ini, mahasiswa membutuhkan Blog/Skype/Youtube ditunjang oleh dosen yang profesional, pembelajaran yang mudah diakses dan tidak membosankan dalam pembelajaran berbasis e-learning.

Saran-saran yang diberikan untuk peningkatan kualitas pelaksanaan $e$-learning yang paling mendesak untuk dipenuhi adalah ketersediaan hotspot dengan akses yang cepat, mengunduh soft copy file materi di web, lebih banyak penggunaan media elektronik, dan mengadakan ujian online.

Implikasi hasil penelitian ini bahwa pelaksanaan pembelajaran e-learning dapat dilakukan dengan adanya tingkat kesiapan dosen dan mahasiswa yang sudah terbiasa dengan perangkat informasi dan teknologi yang, eunjang e-learning. Pembelajaran berbasis e-learning yang juga ditunjang oleh jaringan internet sebagai infra struktur utama yang dapat diakses oleh civitas akademika

\section{PENUTUP}

\section{Kesimpulan}

Dari hasil penelitian yang dilakukan, dapat ditarik beberapa kesimpulan sebagian besar $(+70 \%)$ dosen MKDK sudah menggunakan laptop dan LCD sebagai alat bantu dalam melaksanakan e-learning. Mayoritas dosen (+73\%) tidak menggunakannya CD pembelajaran dan OHP sebagai alat bantu mengajar.

Untuk ketersediaan jaringan hotspot utuk melaksankan e-leaning di dalam kelas di gedung L (FT) lantai 4 tidak ada sama sekali, untuk kemudahan dalam mengakses di gedung L (FT) lantai 3 dan 4 tidak bisa mengakses sama sekali dan untuk kemudahan dalam mengakses di luar kelas di gedung O (FBS) lantai 1 sebanyak $75 \%$ responden menjawab sulit dalam mengakses. Ini berarti hampir di seluruh gedung ketersediaan jaringan hotspot dan kemudahan dalam mengaksesnya masih sangat minim, implikasinya pelaksanaan e-learning belum dapat berjalan efektif.

Penggunaan IT baik oleh dosen dan mahasiswa dalam hal pencarian referensi melalui internet sebagian besar sudah menggunakan internet untuk keperluan perkuliahan yakni sebanyak 89,91. Dosen dalam hal meminta mahasiswa untuk mengumpulkan tugas melalui email, hanya sebagian dosen saja yang sudah melakukannya (hanya 40,3\%). Penggunaan blog di kalangan dosen dalam memberikan materi kuliah 
masih sangat jarang, hanya 10,09\%.

Pelaksanaan e-learning sangat membantu mahasiswa dalam memahami materi kuliah, Dampaknya, mahasiswa merasa senang jika dosen melakukan e-learning dalam pembelajaran. Lebih dari 90\% mahasiswa sudah memiliki laptop dan modem sebagai alat dalam menunjang proses perkuliahan. Lebih dari 86\% mahasiswa menggunakan handphone dalam mengakses materi kuliah. Pemahaman mahasiswa terkait e-learning sudah baik.

Sebagian besar responden setuju dengan pelaksanaan e-learning, karena dengan melaksanakan e-learning memudahkan mahasiswa untuk mengakses materi tanpa terhalang waktu dan tempat, lebih efisien, mudah, cepat dan efektif. Mahasiswa membutuhkan e-learning melalui Blog/Skype/Youtube ditunjang oleh dosen yang profesional, pembelajaran yang mudah diakses, tidak membosankan.

\section{Saran}

Berdasarkan kesimpulan yang telah dikemukakan, maka beberapa saran yang dapat diberikan. Pertama, kepada pihak universitas diharapkan dapat meningkatkan bandwith untuk akses internet agar lebih cepat. Pihak fakultas dan jurusan perlu membantu pihak universitas untuk menyediakan hotpsot yang memudahkan mengakses internet dengan mudah dan cepat.
Kedua, para dosen perlu diberi pelatihan membuat dan menggunakan Blog dan Skype. Para dosen perlu memanfaatkan Blog, Skype, ataupun Youtube sebagai variasi dalam menyampaikan materi pembelajaran. Pihak universitas perlu memenuhi ketersediaan daya dukung seperti aliran listrik yang memadai, serta ketersediaan perangkat proyektor/ LCD di tiap kelas.

\section{DAFTAR PUSTAKA}

Bates, A. W. (1995) Technology, open learning and distance education. London: Routledge.

Handerson, Allan J . (2003) The e-learning question and answer book. New York: Amacom.

Hartley, Darin E. (2001) Selling e-learning. Alexandria: American society for training and development, http:/ / muktiraga.wordpress.com/2007/12/15/elearning/

Koswara, E. (2005). Konsep pendidikan tinggi berbasis e-learning: Peluang dan tantangan. Prosiding Konferensi Nasional Teknologi Informasi dan Komunikasi Indonesia ITB, 3-4 Mei 2005

Natakusumah, E.K. (2002). Multimedia sebagai sarana pembelajaran. Lokakayra Multimedia sebagai sarana pembelajaran metode-learning based; DUE-Like TPB ITB, 13 Nopember 2002.

Tinio, V. L. (2004). ICT In Education. Bangkok: Asia-facific development information programme, 